$\overline{\text { Original }}$

\title{
Synthesis and Antimicrobial Characteristics of Novel Biocides, 1,1'-(Decanedioyl) bis (4-methyl-4- alkylpiperazinium iodide)s with a Gemini Structure
}

\author{
FEI ZHOU, TAKUYA MAEDA*, HIDEAKI NAGAMUNE \\ AND HIROKI KOURAI \\ Department of Biological Science and Technology, Faculty of Engineering, \\ The University of Tokushima, Minamijosanjima-cho, Tokushima 770-8506, Japan
}

Received 8 January 2004/Accepted 10 June 2004

\begin{abstract}
New bis-type quaternary ammonium compounds (QACs), 1,1'-(decanedioyl) bis (4-methyl-4alkylpiperazinium iodide) s (DMAP-n, $n$ : carbon number in the $N$-alkyl chains, $n=6,8,10,12$, $14,16)$, which have a gemini structure containing two piperazinium rings connected with the spacer of the decanedioyl group, were developed. Their antimicrobial characteristics were investigated against 16 strains of bacteria and 9 strains of fungi and compared with those of 1,4-dimethyl-1,4-dialkylpiperazinium diiodides (DMPA-n), 1-methyl-1-alkylpiperazinium iodides (MPA-n), benzyldimethyldodecylammonium chloride (BAC) or 2-(4-thiazolyl)benzimidazole (TBZ). DMAP-10 and DMAP-12 had the highest antimicrobial activity in the DMAP-n series against Escherichia coli K12 W3110 and Staphylococcus aureus IFO 12732. DMAP-12 also exhibited a wide-ranging antimicrobial spectrum, and showed more effective antimicrobial activity against bacteria than DMPA-12 and BAC, and more effective activity against fungi than DMPA-12 and TBZ. The activity of DMAP-12 was not influenced by $\mathrm{pH}$ and temperature like other bis-type QACs. It was found in the DMAP-n, DMPA-n and MPA-n series that the antimicrobial activity and hemolytic activity against human erythrocytes showed some correlation with their molecular hydrophobicity.
\end{abstract}

Key words : Quaternary ammonium compound/Gemini structure/Antimicrobial activity/ 1,1'-(Decanedioyl) bis (4-methyl-4-alkylpiperazinium iodide)s.

\section{INTRODUCTION}

Since the properties and antibacterial activities of quaternary ammonium compounds (QACs) were reported by Jacobs (1916), Jacobs and Heidelberger (1915) and Domagk (1935), they have been widely used in many fields as disinfectants for the environment and surfaces of equipment in hospitals and as antiseptics for wood and leather treatment, the food industry and domestic use. Essentially, this is be-

${ }^{*}$ Corresponding author. Tel : +81-88-656-7519, Fax : + 81-88-656-7519. cause they show high antimicrobial activity with relative safety, a broad antimicrobial spectrum and biodegradability. However, due to their long-term use, resistant microganisms against QACs have appeared. In general, gram-positive bacteria are susceptible to QACs, but it was reported that some Staphylococcus contain genes conveying resistance to this type of disinfectant (Massi et al., 2003; Soprey and Maxey, 1968). Moreover, gram-negative bacteria can prevent the invasion of many chemical products including QACs by modifying their outer membrane. In order to overcome the increase of resistant bacteria, antimicrobial compounds with new molecule structures are necessary. 
It is known that most mono-type QACs have low antifungal activity although they are effective as bactericides. The properties of QACs depend on the covalently bound alkyl groups, which can be highly diverse. It is generally accepted that their mode of action is the disruption of membrane function. Since QACs have positively charged actions, their mode of action is based on their binding to negatively charged materials such as proteins on the bacterial cell surface. Bis-type QACs with divalent charge show more effective antimicrobial activity against both bacteria and fungi than the mono-type QACs, and their activity is little influenced by environmental conditions such as $\mathrm{pH}$ or temperature. QACs with various chemical structures, such as pyridinium salts or piperadinium salts, have been synthesized and their antimicrobial activities have been reported (Kourai et al., 1994b; Maeda et al., 1996). In the recent investigations on the relationship between the antimicrobial activity and chemical structure of QACs, it has been found that bis-type QACs containing a piperazine ring or gemini structure showed a comparatively higher activity against both bacteria and fungi than other QACs or biocides. Thus, the compounds with a structure such as bis-type QACs might be good candidates to work as more effective biocides. Therefore, we developed novel bis-type QACs containing two quaternized piperazine rings connected with the spacer of the decanedioyl group.

The present paper reports the synthesis of new bistype QACs, 1,1'-(decanedioyl) bis (4-methyl-4alkylpiperazinium iodide)s (DMAP-n, n: carbon number in the $N$-alkyl chains, $n=6,8,10,12,14,16$ ), their antimicrobial activities against bacteria and fungi, comparing them with those of 1,4-dimethyl-1,4dialkylpiperazinium diiodides (DMPA-n), 1-methyl-1alkylpiperazinium diiodides (MPA-n), benzyldimethyldodecylammonium chloride (BAC) or 2-(4-thiazolyl)-benzimidazole (TBZ), and the correlations between the antimicrobial activity or hemolytic activity against human erythrocytes and their molecular hydrophobicity in the DMAP-n, DMPA-

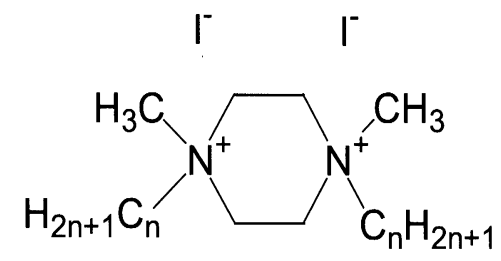

DMPA- $n(n=8,10,12,14$ and 16$)$

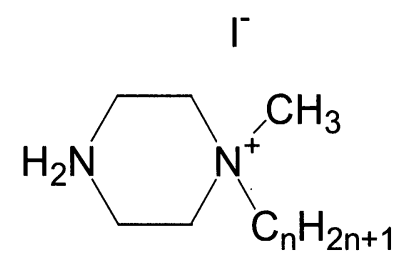

MPA- $n(n=8,10,12,14,16$ and 18)

FIG. 1. Chemical structures of 1,4-dimethyl-1,4dialkylpiperazinium diiodides (DMPA-n) and 1-methyl-1alkylpiperazinium iodides (MPA-n) used as comparative compounds. The abbreviation, $n$, indicates the carbon number of the alkyl chain.

$n$ and MPA-n series.

\section{MATERIALS AND METHODS}

\section{Chemicals}

All chemicals for the syntheses of DMAP-n were reagent grade commercial materials and used without further purification. Alkyl iodides and bromophenol blue (BPB) were purchased from Kanto Chemicals Co., Inc. (Tokyo), 1-methylpiperazine was from Tokyo Chemistry Industry Co., Ltd. (Tokyo), sebacoyl chloride was obtained from Wako Pure Chemical Industries, Ltd. (Osaka). DMPA-n and MPA-n (Fig.1) were synthesized in our laboratory as described before (Kourai et al. 1978). BAC was purchased from Takeda Pharmaceutical Co., Ltd.

TABLE 1. Elemental analysis, melting point and yield of synthesized DMAP-n.

\begin{tabular}{|c|c|c|c|c|c|c|c|c|}
\hline \multirow{3}{*}{ Compounds } & \multicolumn{6}{|c|}{ Elemental analysis (\%) } & \multirow{3}{*}{$\begin{array}{c}\text { Melting } \\
\text { point }\left({ }^{\circ} \mathrm{C}\right)\end{array}$} & \multirow{3}{*}{$\begin{array}{l}\text { Yield } \\
(\%)\end{array}$} \\
\hline & \multicolumn{2}{|c|}{$\mathrm{H}$} & \multicolumn{2}{|c|}{ C } & \multicolumn{2}{|c|}{ N } & & \\
\hline & Calc. & Found & Calc. & Found & Calc. & Found & & \\
\hline DMAP-6 & 8.10 & 7.86 & 48.61 & 48.44 & 7.09 & 7.12 & $211-213$ & 31.7 \\
\hline DMAP-8 & 8.51 & 8.36 & 51.06 & 50.86 & 6.62 & 6.63 & $205-207$ & 35.9 \\
\hline DMAP-10 & 8.85 & 8.70 & 53.09 & 52.89 & 6.24 & 6.20 & 194-196 & 31.3 \\
\hline DMAP-12 & 9.19 & 8.96 & 55.11 & 54.95 & 5.85 & 5.75 & $200-201$ & 32.1 \\
\hline DMAP-14 & 9.47 & 9.28 & 56.80 & 56.74 & 5.52 & 5.45 & $208-210$ & 33.4 \\
\hline DMAP-16 & 9.72 & 9.59 & 58.32 & 58.10 & 5.24 & 5.13 & $215-217$ & 31.4 \\
\hline
\end{tabular}




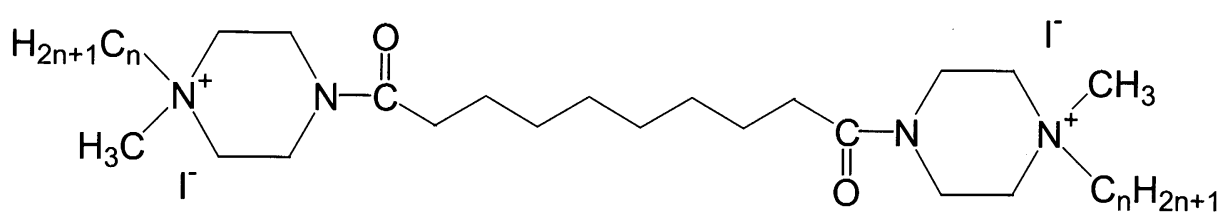

DMAP- $n(n=6,8,10,12,14$ and 16)

FIG. 2. Chemical structure of $1,1^{\prime}$-(decanedioyl) bis (4-methyl-4-alkylpiperazinium iodide)s (DMAP-n). The abbreviation, $n$, indicates the carbon number of the alkyl chain.

(Osaka) and TBZ was purchased form San-ai Oil Co. Ltd. (Tokyo).

\section{Preparation of DMAP-n}

Sebacoyl chloride $(0.01 \mathrm{~mol})$ in absolute benzene (100ml) as a solvent was cooled down to $10{ }^{\circ} \mathrm{C}$ and 1-methylpiperazine $(0.04 \mathrm{~mol})$ was slowly dropped into the solution undergoing continuous stirring. After the addition, the reaction was continued for $2 \mathrm{~h}$ at room temperature. The precipitate was removed by filtration and the filtrate was concentrated to the volume of $50 \mathrm{ml}$ with a rotary evaporator under a reduced pressure. The concentrated filtrate was refluxed for $5 \mathrm{~h}$ at $80{ }^{\circ} \mathrm{C}$ after the addition of $0.04 \mathrm{~mol}$ of $n$-alkyl iodide (hexyl iodide, octyl iodide, decyl iodide, dodecyl iodide, tetradecyl iodide and hexadecyl iodide). Finally, the reaction mixtures were filtrated and the recovered precipitates were recrystallized from ethanol.

The purity of the synthesized compounds was checked by the measurement of the melting point and elemental analysis. The melting point was measured with a melting point apparatus (Mitamura Riken Kogyo Inc., Tokyo) and elemental analysis was done with an elemental analysis apparatus (MT-5, Yanagimoto, Tokyo). The chemical structures of compounds were analyzed by proton nuclear magnetic resonance ( ${ }^{1} \mathrm{H}-\mathrm{NMR}$ ) spectra measured in $\mathrm{CD}_{3} \mathrm{OD}$ with an NMR spectrometer (JEM-EX400, $400 \mathrm{MHz}$, JEOL, Tokyo), using tetramenthylsilane as an internal standard.

As shown in Table 1, the data of the elemental analysis, melting point and yield of DMAP-n agreed with their theoretical values. The NMR data are consistent with the proposed structures of all compounds in DMAP-n series (Fig.2). The following data on DMAP-12 is given as a typical result. The signal of $0.91 \mathrm{ppm}(6 \mathrm{H}, \mathrm{t})$ indicated the terminal methyl protons of chain bonded to the ammonium nitrogen. The signals of $1.32 \mathrm{ppm}(44 \mathrm{H}, \mathrm{m})$ and $1.81 \mathrm{ppm}(4 \mathrm{H}, \mathrm{m})$ were assigned to the methylene protons of the alkyl chain on the sides and in the middle of spacer. With regard to the methylene protons bonded to the ammonium nitrogen, a chemical shift at $3.10 \mathrm{ppm}(4 \mathrm{H}, \mathrm{t})$ was seen. The methyl protons directly bonded to the ammonium nitrogen showed a signal of $3.35 \mathrm{ppm}$ $(6 \mathrm{H}, \mathrm{s})$. The signals of $3.50 \mathrm{ppm}(8 \mathrm{H}, \mathrm{t})$ and 3.68 ppm $(8 \mathrm{H}, \mathrm{t})$ were assigned to the methylene protons at the 2, 3, 4 and 5-positions of the piperazine rings. The chemical shifts of methylene protons in the alkyl chain connecting two carbonyl bonds were detected at $2.40 \mathrm{ppm}(4 \mathrm{H}, \mathrm{m})$ and $1.61 \mathrm{ppm}(4 \mathrm{H}, \mathrm{m})$. The NMR data on the other compounds are also consistent with their structures (data not shown).

\section{Microbes, cultivation and preparation}

Escherichia coli K12 W3110 and Staphylococcus aureus IFO 12732 were employed for the experiments. Bacteria and fungi were prepared according to a previous study (Maeda et al., 1999).

\section{Determination of antimicrobial activity}

Antibacterial and antifungal activities of synthesized compounds were evaluated by minimum bactericidal concentration ( $\mathrm{MBC}$, expressed in $\mu \mathrm{mol} / \mathrm{l}$ ) and minimum inhibitory concentration (MIC, expressed in $\mu \mathrm{mol} / \mathrm{l})$ using the standard broth dilution method (Kourai et al., 1995). Bacteriostatic activity and bactericidal activity were defined as Log MIC $(\mathrm{M})^{-1}$ and $\log \mathrm{MBC}(\mathrm{M})^{-1}$, respectively.

\section{Determination of hemolytic activity against hu- man erythrocytes}

Hemolytic activity was estimated as the minimum hemolysis concentration ( $\mathrm{MHC}$ ) determined by the method reported previously (Pérez et al., 2002). Human blood was mixed with the same volume of Alseber's solution (glucose, $20.5 \mathrm{~g} ; \mathrm{NaCl}, 4.2 \mathrm{~g}$; trisodium citrate, $8.0 \mathrm{~g}$; citric acid, $0.55 \mathrm{~g}$, per liter, $\mathrm{pH}$ 6.1) and kept at $4{ }^{\circ} \mathrm{C}$. Right before being used, the supernatant and leucocyte fractions were removed by centrifugation ( $1500 \times g, 4{ }^{\circ} \mathrm{C}, 5 \mathrm{~min}$ ). With PBS solution $\left(\mathrm{NaCl}, 8 \mathrm{~g} ; \mathrm{Na}_{2} \mathrm{HPO}_{4} \cdot 12 \mathrm{H}_{2} \mathrm{O}, 2.9 \mathrm{~g} ; \mathrm{KCl}, 0.2 \mathrm{~g}\right.$; $\mathrm{KH}_{2} \mathrm{PO}_{4}, 0.2 \mathrm{~g}$, per liter, $\mathrm{pH}$ 7.2), erythrocytes were washed three times and diluted to $50 \%(\mathrm{~V} / \mathrm{V})$. Ten micro liters of erythrocyte suspension were mixed with $990 \mu \mathrm{l}$ of PBS solution containing different concentrations of DMAP-n and kept for $1 \mathrm{~h}$ at $37^{\circ} \mathrm{C}$. After 


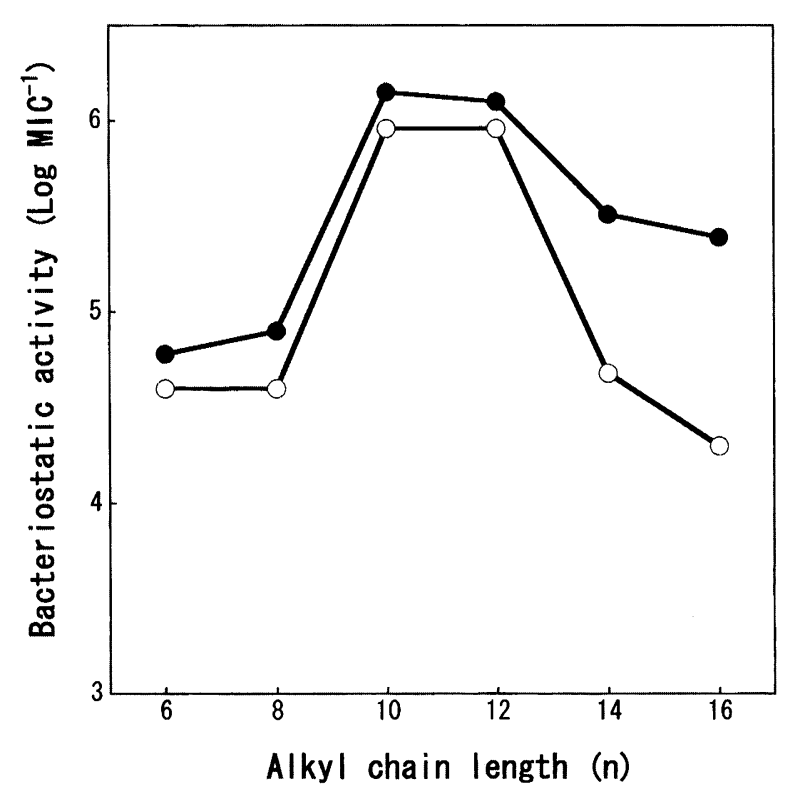

FIG. 3. Relations between the alkyl chain length and the bacteriostatic activity of DMAP-n against E. coli K12 W3110 and S. aureus IFO 12732. Symbols: O, S. aureus ; $\bigcirc$, E. coli.

incubation, reaction mixtures were centrifuged ( 1500 $\times g, 4{ }^{\circ} \mathrm{C}, 5 \mathrm{~min}$ ), and the optical density of each supernatant was measured at a wave length of $540 \mathrm{~nm}$. The rate of lysed erythrocytes was determined by comparison with the control, $10 \mu \mathrm{l}$ of erythrocyte suspension to which was added $990 \mu \mathrm{I}$ of PBS solution without an antimicrobial compound. The lowest concentration of each antimicrobial agent to lyse erythrocytes in the reaction mixture was defined as $\mathrm{MHC}$.

\section{Determination of molecular hydrophobicity}

Molecular hydrophobicities of antimicrobial agents were measured by the method reported previously (Maeda, et al., 1996).

\section{RESULTS}

\section{Relationship between the alkyl chain length and the antibacterial activity}

Generally, it has been known well that the alkyl chain length attached to the ammonium nitrogen is closely related with the activity of QACs as a sanitizer. The antibacterial activities of DMAP-n with various alkyl chain lengths against $S$. aureus IFO 12732 and $E$. coli K12 W3110 were investigated and the results are shown in Fig.3. Their antibacterial activities were influenced by the alkyl chain length, and were at a maximum with $\mathrm{C} 10$ and $\mathrm{C} 12$. In the case of E. coli K12 W3110, DMAP-n showed lower antibacterial activities than in the case of $S$. aureus IFO 12732. Although DMAP-16 was not completely dissolved in the medium at the prescribed concentration because of its high hydrophobicity, it also showed a high level of activity, especially against S. aureus IFO 12732.

Judging from the above results, DMAP-12 was selected for the following investigations.

\section{Antibacterial activity and antibacterial spectrum}

The antibacterial spectra of DMAP-12, DMPA-12 and BAC were comparatively investigated at $37^{\circ} \mathrm{C}$ against Gram-negative bacteria (10 strains) and Gram-positive bacteria (6 strains), and the results are shown in Table 2. DMAP-12 exhibited a stronger antibacterial activity against all bacteria tested in this

TABLE 2. MICs of DMAP-12, DMPA-12 and BAC against bacteria.

\begin{tabular}{|c|c|c|c|}
\hline Strains & DMAP-12 & DMPA-12 & BAC \\
\hline Pseudomonas aeruginosa ATCC 27583 & $6.3^{a}$ & 25.0 & 50.0 \\
\hline Pseudomonas aeruginosa ATCC 10145 & 5.2 & 25.0 & 50.0 \\
\hline Pseudomonas aeruginosa ATCC 3080 & 1.6 & 6.3 & 66.7 \\
\hline Klebsiella pneumoniae ATCC 4352 & 0.4 & 3.1 & 12.5 \\
\hline Klebsiella pneumoniae ATCC 13883 & 0.8 & 12.5 & 41.7 \\
\hline Proteus vulgaris ATCC 13315 & 0.4 & 1.6 & 16.7 \\
\hline Proteus mirabilis NBRC 3849 & 6.3 & 12.5 & 100.0 \\
\hline Escherichia coli K12 W3110 & 0.8 & 4.2 & 25.0 \\
\hline Escherichia coli IFO 3301 & 0.2 & 6.3 & 25.0 \\
\hline Escherichia coli IFO 3972 & 1.3 & 12.5 & 33.3 \\
\hline Bacillus subtilis IFO 3134 & 0.8 & 3.1 & 5.2 \\
\hline Bacillus subtilis ATCC 6633 & 0.8 & 6.3 & 6.3 \\
\hline Bacillus cereus IFO 3001 & 0.4 & 6.3 & 6.3 \\
\hline Bacillus megaterium IFO 3003 & 0.3 & 3.1 & 6.3 \\
\hline Staphylococcus aureus ATCC 25923 & 0.3 & 2.6 & 5.2 \\
\hline Staphylococcus aureus IFO 12732 & 0.4 & 3.1 & 12.5 \\
\hline
\end{tabular}

${ }^{a} \mathrm{MICs}(\mu \mathrm{M})$ measured by the broth dilution method with nutrient broth at $37^{\circ} \mathrm{C}$ for $24 \mathrm{~h}$. 
TABLE 3. MICS of DMAP-12, DMPA-12 and BAC against fungi.

\begin{tabular}{lcrr}
\hline \multicolumn{1}{c}{ Strains } & DMAP-12 & DMPA-12 & TBZ \\
\hline Aspergillus niger IFO 6341 & $8^{a}$ & 31 & 62 \\
Aspergillus niger IFO 6342 & 4 & 250 & 250 \\
Aspergillus niger IFO 4414 & 4 & 125 & 207 \\
Chaetomium globosum IFO 6347 & 8 & 62 & 333 \\
Rhizopus oryzae IFO 31005 & 2 & 62 & 125 \\
Penicillium citrinum IFO 6352 & 8 & 250 & 83 \\
Aureobasidium pullulans IFO 6353 & 16 & 62 & 31 \\
Cladosporium cladosporioides IFO 6348 & 4 & 31 & 62 \\
Gliocladium virens IFO 6355 & 8 & 125 & 21 \\
\hline
\end{tabular}

${ }^{a} \mathrm{MICs}(\mu \mathrm{M})$ measured by the broth dilution method with Sabouraud broth at $30^{\circ} \mathrm{C}$ for $2 \mathrm{~d}$.

study than other compounds compared. As described in our previous reports, mono-QACs as cationic surfactants show higher activities against Gram-positive bacteria than against Gram-negative bacteria, because the bacteria with comparatively hydrophobic cell surfaces such as Gram-positive bacteria tend to be sensitive to mono-QACs. However, the antibacterial activities of bis-QACs are not dependent on the hydrophobicity of the bacterial cell surface and are effective against a wide range of bacteria. The results in this experiment proved the tendency mentioned above once again, and moreover indicated that the bis-QAC with a gemini structure is more effective than the common monomer type and is a novel potential biocide.

\section{Antifungal activity and antifungal spectrum}

The antifungal spectra of DMAP-12, DMPA-12 and TBZ (a very commonly used fungicide) were examined at $30^{\circ} \mathrm{C}$ against 9 strains of fungi, and the results are shown in Table 3. Mono-QACs are generally not effective against fungi (Kourai et al., 1994b). DMAP12 exhibited a wide spectrum of action and a high antifungal activity and was more effective than DMPA-12 and TBZ against all of the fungi listed in Table 3. Moreover DMAP-12 had an antifungal activity (MIC) close to other bis-QACs reported by Maeda et al. (1999), Okazaki et al. (1997) and Yoshida et al. (2000).

\section{Effect of temperature and pH on antibacterial ac- tivity}
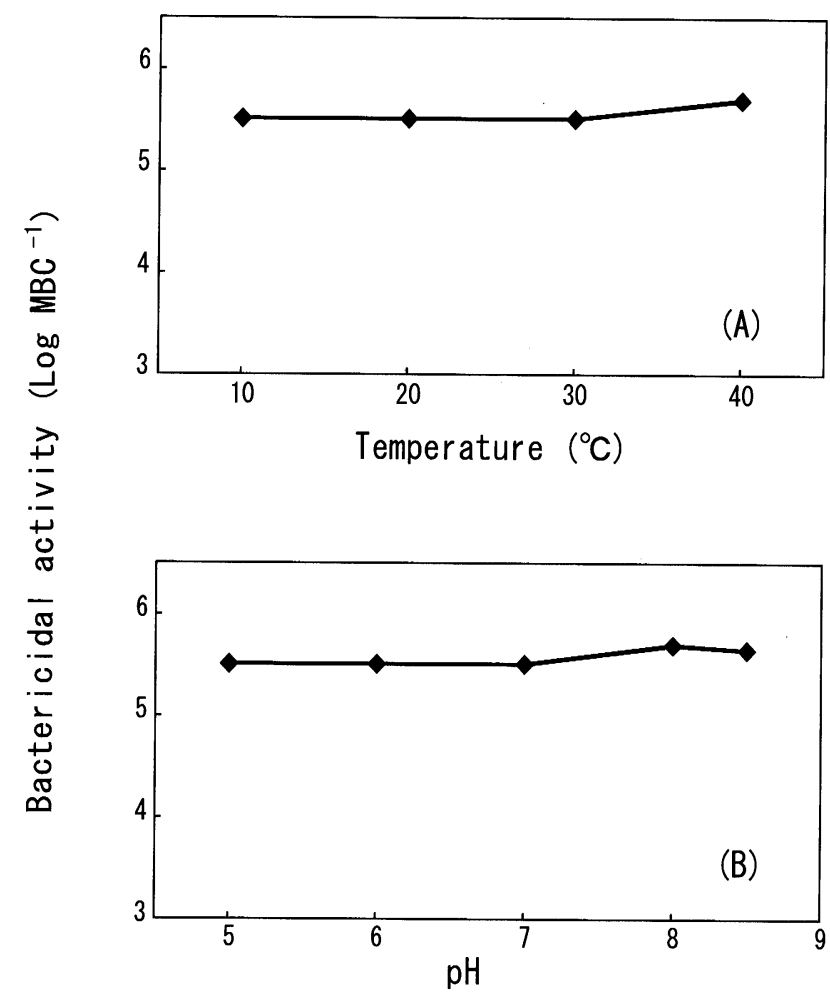

FIG. 4. (A) Effect of temperature on the bactericidal activity of DMAP-12 against $E$. coli K12 W3110. The bactericidal activity was measured using sterilized distilled water at the prescribed temperature for $30 \mathrm{~min}$. (B) Effect of $\mathrm{pH}$ on the bactericidal activity of DMAP-12 against $E$. coli K12 W3110. The bactericidal activity was measured using $5 \mathrm{mM}$ phosphate buffer prepared at the prescribed $\mathrm{pH}$ values instead of sterilized distilled water at $30{ }^{\circ} \mathrm{C}$ for $30 \mathrm{~min}$.

TABLE 4. MHCs of DMAP-n, DMPA-n and MPA-n against human erythrocytes.

\begin{tabular}{lccccccc}
\hline \multirow{2}{*}{ Compounds } & \multicolumn{7}{c}{$\mathrm{n}$} \\
\cline { 2 - 8 } & 6 & 8 & 10 & 12 & 14 & 16 & 18 \\
\hline DMAP-n & $62.0^{a}$ & 31.0 & 15.5 & 15.5 & 15.5 & 31.0 & - \\
DMPA-n & - & 41.3 & 13.0 & 8.0 & 8.0 & 20.7 & - \\
MPA-n & - & 62.0 & 31.0 & 31.0 & 41.3 & 83.3 & 83.3 \\
\hline
\end{tabular}

${ }^{a} \mathrm{MHC}(\mu \mathrm{M})$. 
To evaluate the influence of temperature on antibacterial activity, the MBC of DMAP-12 was measured at 10, 20,30 and $40{ }^{\circ} \mathrm{C}$. As shown in Fig.4(A), it was proved that the temperature of environment hardly influenced the antibacterial activity of DMAP12 , though temperature is generally a major factor affecting the effectiveness of QACs as disinfectants.

MBCs of DMAP-12 were measured using phosphate buffers prepared at various values of $\mathrm{pH}(5,6$, 7,8 and 8.5 ) instead of sterilized distilled water and the results are shown in Fig.4(B). DMAP-12 showed a constantly high activity in the full $\mathrm{pH}$ range from 5 to 8.5. It is known that mono-QACs are more effective in an alkaline solution than acidic solution (Kourai et al., 1994a; Maeda et al., 1996). However, the antibacterial activity of DMAP-12 has no correlation with $\mathrm{pH}$ and showed a constantly high value.

\section{Hemolytic activity against human erythrocytes}

Hemolytic activities of all compounds in DMAP-n, DMPA-n and MPA-n series against human erythrocytes were investigated (Table 4). Hemolytic activities of the compounds were affected by the length of alkyl chain, and on the whole they were at a maximum with $\mathrm{C} 10, \mathrm{C} 12$ and $\mathrm{C} 14$. This tendency was similar to that of the effect of alkyl chain length on antibacterial activity, which may suggest that their hemolysis mechanism and antimicrobial mechanism have something in common.

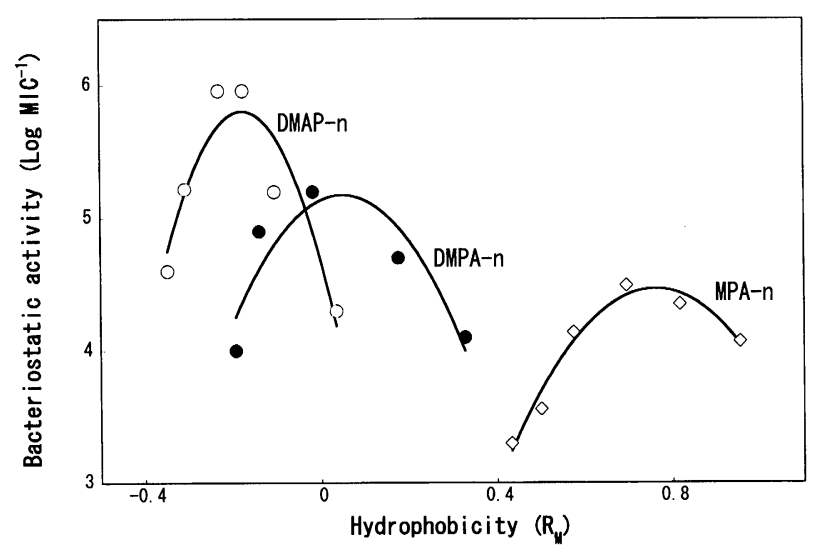

FIG. 5. Relations between the molecular hydrophobicity and bacteriostatic activity of three types of QACs. Hydrophobicity is expressed as $R_{M}$ and was evaluated by the equation as follows: $R_{M}=\log \left(1 / R_{f}-1\right)$. Symbols: $O$, DMAP-n; DMPA-n; $\diamond$, MPA-n. Solid lines represent the equations: DMAP-n, $\log \mathrm{MIC}^{-1}=4.68-12.8 R_{M}-36.1 R_{M}^{2}$, $\mathrm{r}=0.932, \mathrm{t}=5.16\left(\mathrm{t}_{0.01(4)}=4.60\right) ;$ DMPA-n, $\log \mathrm{MIC}^{-1}=5.14+$ $1.56 R_{M}-15.4 R_{M}^{2}, r=0.892, t=3.41\left(t_{0.05(3)}=3.18\right) ;$ MPA-n, log $\mathrm{MIC}^{-1}=-2.07+17.2 R_{M}-11.3 R_{M}^{2}, \quad r=0.981, \quad \mathrm{t}=3.41 \quad\left(\mathrm{t}_{0.01(4)}=\right.$ 4.60).

\section{Relationship between antibacterial activity and molecular hydrophobicity}

Molecular hydrophobicities of DMAP-n, DMPA-n and MPA-n, were determined and the results were plotted with reference to their antibacterial activities (MIC) against $E$ : coli K12 W3110 in Fig. 5. There was a good quadratic correlation between the hydrophobicity and antibacterial activity $\left(\log \mathrm{MIC}^{-1}\right)$ of each compound within one series. DMAP-n had the lowest hydrophobicity compared with DMPA-n and MPA- $n$ in the case of the same carbon chain length. DMPA-n was next and MPA-n was the highest.

\section{DISCUSSION}

Since a new type of surfactant molecule, with a dimeric structure called Gemini, was synthesized in 1974 (Zhao et al., 2002), this kind of surfactant has been generating, increasing interest owing to their superior performance in actual application. A short hydrocarbon spacer connects two charged polar heads with a long hydrocarbon chain, respectively. As a result, the two molecules of ammonium salt are held at a shorter distance than when electrostatic repulsion between the positive charges is exerted freely. That is why the gemini structure can give special surface properties different from those of a conventional single-chain surfactant with the same number of carbon atoms per polar head group. Monomeric surfactants generally form spherical micelles, but gemini typically form elongated aggregates (Oda et al., 1999). Therefore, the gemini surfactant has higher surface activity than the conventional single-chain one (Zheng, et al., 2001).

In the present study, a series of bis-quaternary ammonium salts, DMAP- $n(n=6,8,10,12,14,16)$, was synthesized and their antimicrobial characteristics were investigated. In the series of DMAP-n, an excellent antimicrobial action of DMAP-12 was observed against bacteria and fungi and far exceeded those of DMPA-12, MPA-12 with similar chemical structures and BAC which is used most commonly. The activity of DMAP-12 was not influenced by $\mathrm{pH}$ and temperature like other bis-QACs (Maeda et al., 1999; Okazaki et al., 1997; Yoshida et al., 2000). Thus, it is implied that the excellent antimicrobial activities of bis-QACs with the gemini structure as DMAP-12 are closely related to their unique dimeric cation structure. To clarify the mode of action of a bis-QAC, 4,4'-(1,6hexamethylenedithio) bis (1-octylprydinium bromide) (4DTBP-6,8) against E. coli, Sumitomo et al. (2003) kinetically analyzed its bactericidal activity compared with that of a mono-QAC, $N$-octylpyridinium bromide (P-8). Consequently, it was proved that the 
difference between a bis-QAC and a mono-QAC is due to the activation energy of bactericidal action calculated from the Arrhenius plots of the rate constant. Moreover, the hemolytic activity of DMAP-n remained at the same level of DMPA-n and MPA-n, although the antibacterial activity of the former was higher. Therefore, it is considered that DMAP-12 might be a novel and potential cationic biocide for commercial use.

Devinsky et al. (1996) and Pavlikova-Moricka et al. (1994) demonstrated a relationship between hydrophobicity and the antibacterial activity of 4alkyl-4-ethylmorpholinium bromides and bis-QAC derived from bis-(2-dimethylaminoethyl) glutarate which have different alkyl groups, using the QSAR method. Kourai et al. (1994b) have also reported that the antibacterial activity of $\mathrm{N}$-alkyl-4-butenylpyridinium bromides was correlated with their hydrophobicity. Based on our results in Fig.5, there were remarkable differences in the antibacterial activity between two kinds of bis-QACs with the same or comparable hydrophobicity, for example, DMAP-12 and DMPA-8. This observation suggests that not only antibacterial activity of bis-QACs is obviously affected by molecular hydrophobicity or the alkyl chain, but also that the activity is related to parts of the molecule other than the alkyl chain, for example, the position and number of hydrophobic or hydrophilic groups in an antimicrobial molecule. The antibacterial activity seems to depend on the balance between the hydrophilicity from the polar head group and the hydrophobicity from the nonpolar alkyl group. It is necessary to assess the relationship between the antimicrobial activity and the gemini structure of quaternary ammonium salt as DMAP-12 at the molecular level.

\section{REFERENCES}

Devinsky, F., Zamocka, J., Lacko, I., and Polikovicova, M. (1996) QSAR and CAMM study of amphiphilic antimicrobially active 2,2'-bipyridylmonoammonium salts. Pharmazie, 51, 727-731.

Domagk, G. (1935) Eine neue klasse von disinfectionsmitteln (in German). Dtsch. Med. Wochenschr., 61, 829-832.

Jacobs, W. A., and Heidelberger, M. (1915) The quaternary salts of hexamethylenetetramine I. Substituted benzyl halides and the hexamethylenetetrammoniums salts derived therefrom. J. Biol. Chem., 20, 659-683.

Jacobs, W. A. (1916) The bactericidal properties of the quaternary salts of hexamethylenetetramine I. The problem of the chemotherapy of experimental bacterial infections. J. Exp. Med., 23, 563-568.

Kourai, H., Sato, T., Uchiwa, N., Takeichi, K., and Shibasaki, I. (1978) The antibacterial characteristics of quaternary salts (in Japanese). J. Antibact. Antifung. Agents, 6, 1118.

Kourai, H., Oda, K., Takechi, H., and Nakagawa, K. (1994a) The antibacterial characteristics of poly[dimethylimino (polymethylene) chloride]s. J. Antibact. Antifung. Agents, 22, 519-530.

Kourai, H., Hasegawa, Y., and Wada, K. (1994b) Bactericidal characteristics of N-alkyl-4-buteneylpyridinium bromides. J. Antibact. Antifung. Agents, 22, 653-661.

Kourai, H., Manabe, Y., Matsutani, E., Hasegawa, Y., and Nakagawa, K. (1995) Antimicrobial activities of alkylallyldimethylammonium iodides and alkylallyldiethylammonium iodides. J. Antibact. Antifung. Agents, 23, 271-280.

Maeda, T., Goto, S., Manabe, Y., Okazaki, K., Nagamune, $\mathrm{H}$., and Kourai, H. (1996) Bactericidal action of $\mathrm{N}$ alkylcyanopyridinium bromides against Escherichia coli K12 W3110. Biocontrol Sci., 1, 41-49.

Maeda, T., Yoshida, M., Manabe, Y., Okazaki, K., Nagamune, H., and Kourai, H. (1999) Synthesis and antimicrobial characteristics of 5,5'-[2,2'-(tetramethylenedicarbonyldioxy) diethyl] bis (3-alkyl-4-methylthiazolium iodide)s. Biocontrol Sci., 4, 75-81.

Massi, L., Guitard, F., Geribaldi, S., Levy, R., and Duccini, Y. (2003) Antimicrobial properties of highly fluorinated bisammonium salts. Int. J. Antimicrob. Agents, 21, 20-26.

Oda, R., Hue, I., Homo, J. -C., Heinrich, B., Schmutz, M., and Candau, S. (1999) Elongated aggregates formed by cationic gemini surfactant. Langmuir, 15, 2384.

Okazaki, K., Maeda, T., Nagamune, H., Manabe, Y., and Kourai, H. (1997) Synthesis and antimicrobial characteristics of $4,4^{\prime}-(\alpha, \omega$-polymethylenedithio) bis (1-alkylprydinium iodide)s. Chem. Pharm. Bull., 45, 1970-1974.

Pavlikova-Moricka, M., Lacko, I., Devinsky, F., Masarova, L., and Mlynarcik, D. (1994) Quantitative relationship between structure and antimicrobial activity of new "soft" bisquaternary ammonium salts. Folia Microbiol., 39, 176180.

Perez, L., Garcia, M. T., Ribosa, T., Vinardell, M. P., Manresa, A., and Infante, M. R. (2002) Biological properties of arginine-based gemini cationic surfactants, Environ. Toxicol. Chem., 21, 1279-1285.

Soprey, P., and Maxey R. (1968) Tolerance of bacteria for quaternary ammomium compounds. J. Food Sci., 24, $141-150$

Sumitomo, T., Maeda, T., Nagamune, H., and Kourai, $H$. (2003) Kinetic analysis of the bactericidal action of a bisquaternary ammonium compound against Escherichia coli. Biocontrol Sci., 8, 145-149.

Yoshida, M., Maeda, T., Okazaki, K., Nagamune, H., Kunikata, K., Tsuchiya, H., Namba, T., and Kourai, H. (2000) Synthesis and antimicrobial characteristics of $N, N^{\prime}$-hexamethylenebis (4-carbomoyl-1-decylpyridinium bromide). Biocontrol Sci., 5, 65-71.

Zhao, Z. K., Qiao, W. H., and Li, Z. S. (2002) The newest research for gemini surfactant. Chem. Online, 65, 81-93.

Zheng, L. Q., Shui, L. L., You, L., Zheng, Q., Li, Y., Zhao, J. X., and Li, G. Z. (2001) The surface tension study of the gemini surfactant solutions (in Chinese). Acta Chim. Sinica., 59, 637-642. 